\title{
Entrepreneurial Bricolage, Dynamic Capabilities and Disruptive Innovation: Theoretical Model
}

\author{
Cao Ning, Miao Xiaoming, and Shang Tiantian
}

\begin{abstract}
Disruptive innovation has gradually become one of the focuses of entrepreneurship research. Based on the comprehensive perspective of resource-based view and dynamic capabilities view, this study analyzed the relevant literature, built a theoretical model of entrepreneurial bricolage, dynamic capabilities and disruptive innovation, and extracted relevant propositions. This research provides new insights into the development of disruptive innovation theory and the strategic management practices of entrepreneurial enterprises.
\end{abstract}

Index Terms-Disruptive innovation, entrepreneurial bricolage, dynamic capabilities, entrepreneurial enterprises.

\section{INTRODUCTION}

Disruptive innovation, first proposed by Christensen [1], explains why mature enterprises with good management, competitiveness and execution capabilities lose market dominance. Disruptive innovation can develop new markets, destroy the existing market structure, and have a significant impact on management practice. Therefore, it has become the focus and frontier of innovation theory and strategic management theory. Entrepreneurial enterprises have become important driving forces for China's sustained economic growth, which play an important role in promoting public innovation, national employment and increasing national income. In order to achieve "stand out" in the fierce competition, disruptive innovation provides leapfrog development opportunities for entrepreneurial enterprises, but the failure of disruptive innovation caused by the liability of newness is ubiquitous.

In the practice of entrepreneurship, most start-ups are faced with resource constraints [2]. Therefore, how to break through resource constraints has become a hot spot in entrepreneurial research. The resource-based view emphasizes that competitive advantage comes from unique resources, but does not clearly state where heterogeneous resources come from. During the period of China's transformation, the market system is not perfect enough, and there are many difficulties for entrepreneurial enterprises to obtain resources. The theory of entrepreneurial bricolage is an effective way for enterprises to break through resource constraints. However, the pooled resources have a certain timeliness, that is, they can only bring good performance for the enterprise in a certain period of time. With the

Manuscript received June 18, 2019; revised September 15, 2019. This work was supported by the National Social Science Foundation of China (Grant No. 18BGL033).

Cao Ning, Miao Xiaoming, and Shang Tiantian are with Northwestern Polytechnical University, Xi'an Shaanxi, China (email: 13837977762@139.com, 1078086536@qq.com, 877543483@qq.com). development of the enterprise and the change of the external environment, these resources will be gradually exhausted or ineffective. Entrepreneurial enterprises are not only affected by resources, but also by internal capabilities. Therefore, in the process of resource bricolage, enterprises must form a kind of unique capability, that is, dynamic ability, which can respond to the changes of external environment quickly and bring sustainable competitive advantage to enterprises [3]. Enterprises with strong dynamic capabilities can strengthen the allocation of existing resources, so that they can quickly meet market demand. The dynamic capabilities view holds that in a vague and unpredictable market environment, the capability of enterprises to integrate, construct and reconfigure their internal and external resources is the source of their sustainable competitive advantage. Resources are the foundation of capabilities. It is a new attempt to integrate the resource-based view and dynamic capabilities view into a framework to study the relationship between entrepreneurial bricolage and dynamic capabilities and their impact on disruptive innovation of entrepreneurial enterprises. It is of great significance for the disruptive innovation growth of entrepreneurial enterprises to combine the entrepreneurial bricolage and dynamic capabilities through resource links.

Based on this, this study attempts to explore the disruptive innovation growth of entrepreneurial enterprises on the basis of comprehensive analysis of the existing literature, try to build a theoretical model of the disruptive innovation process and put forward relevant propositions, in order to promote the development of the disruptive innovation theory and practice of entrepreneurial enterprises.

\section{THEORETICAL BASIS}

\section{A. Disruptive Innovation}

Innovation behavior and activities can win more market development opportunities for enterprises. Technology has become a key factor in the process of innovation. Technology-driven innovation includes two types: Sustainable innovation and disruptive innovation. Compared with sustainable innovation, disruptive innovation has strong forward-looking and exploratory advantages, and has a more positive role in creating markets and shaping customer preferences, and even changing consumers' basic behaviors [4]. The existing research explores the internal mechanism of disruptive innovation from the perspective of the influencing factors and processes.

Scholars have studied the influencing factors of disruptive innovation. Karimi and Walter [5] argued that top managers' support for disruptive innovation is not only strategically 
important, but also actively involved in these projects. Dedrick et al. [6] believed that innovation culture, such as entrepreneurship, risk-taking, flexibility and creativity, can promote enterprises to pursue disruptive technology, and innovation culture should be protected and valued. Nadine et al. [7] based on the concept of organizational identity, proposed that domain identity and role identity together determine the response speed of incumbents to disruptive innovation. Age and scale of enterprises also influence disruptive innovation. Ghezzi et al. [8], Hynes and Elwell [9], Dedrick et al. [10] believed that small start-ups are not affected by existing customers' demands to improve existing products and flexibly product and sale products with two advantages: flexibility of marketing strategy and short time to market. Start-ups are not influenced by bureaucracy, constantly experimenting with new technologies, have the opportunity to introduce disruptive technologies, and are more capable of commercializing disruptive technologies, triggering truly disruptive innovation. Innovation activities are highly dependent on resources. Parry and Kawakami [11] and Karimi and Walter [12] argued that disruptive innovation projects cannot succeed without adequate allocation of financial and human resources. Even if the company has sufficient resources, Karimi and Walter [12] believed that it is difficult for companies to prioritize the allocation of funds for disruptive innovation projects because these projects are generally considered unlikely to generate considerable profits.

Scholars have explored the dynamic process of disruptive innovation from the perspective of market invasion. Christensen and Reynor [13] distinguished between low-end disruption and new market disruption. Low-end disruptione mainly uses low-cost strategies to meet the needs of mainstream low-end consumers, then spreads upward and gradually opens up the market. New market disruption mainly meets the needs of non-mainstream consumers who have never used existing products by developing simple and cheap products, by adopting low-cost strategies to meet the needs of mainstream low-end consumers, and then attract more mainstream customers by improving product performance. With the deepening of the research, Schmidt and Druehl [14] supplemented Christensen's research, believed that the new market disruption mainly starts from the low end of marginal market or separated market to the mainstream market, and the low-end disruption diffusion mode starts directly from the low end of the mainstream market. Govindarajan [15] further discussed that the diffusion model of disruptive innovation is not limited to low-end intrusion, but also includes high-end intrusion. New products first grab the mainstream high-end consumers, and then spread downward until low-end consumers begin to use disruptive products.

Disruptive innovation plays a key role in the process of enterprise entrepreneurship. It can avoid the pursuit of the ultimate in every dimension of product attributes, thereby reducing costs and providing relatively low product prices. Disruptive innovation usually develops by exploring the cracked market and then gradually penetrating into the mainstream market. Disruptive products can change the behavior of end users and the mainstream market rules.
Existing research on disruptive innovation focuses on the influencing factors and dynamic process of disruptive innovation, but the research objects are mostly focused on mature enterprises or latecomer enterprises, and there are few studies on disruptive innovation of entrepreneurial enterprises.

\section{B. Dynamic Capabilities}

On the basis of the analysis and discussion of the school of competitive mechanics, game theory and resource-based theory in strategic management, Teece et al. [16] put forward the theory of dynamic capabilities, investigating how enterprises can adapt to the rapidly changing environment with the new capabilities generated by integrating, constructing and reconfiguring internal and external resources and capabilities. Subsequent scholars have defined dynamic capabilities from the perspectives of level, process, learning and resources. Winter [17] put forward that dynamic capability is regarded as "first-order" capability, aiming at intentionally changing the market of products, production processes, standards or services. Eisenhardt and Martin [18] argued that dynamic capabilities are the process of transforming existing resources into new resources and resource combinations to adapt and even create market changes. Zollo and Winter [19] emphasized that dynamic capability is learning capability, which enables enterprises to systematically create and adjust operation management to improve efficiency of collective activities. Helfat et al. [20] proposed that dynamic capability is the capability of an organization to purposefully create, expand and adjust its resource base.

Many scholars have discussed the dimension of dynamic capabilities, but they have not formed a consensus. Teece [21] believed that dynamic capabilities consist of sensing opportunities capability, seizing opportunities capability and resource reconfiguration capability. Wang and Ahmed [22] classified dynamic capabilities as adaptive, absorptive and innovative capabilities. Barreto [23] decomposed dynamic capabilities into resource integration capability, resource reallocation capability, learning capability, adaptability and innovation capability. Pavlou and El Sawy [24] subdivided dynamic capabilities into perception, learning, integration and coordination. Dimensional division of dynamic capabilities has not yet formed a more unified conclusion, which shows that dynamic capabilities are complex. Most scholars understand dynamic capabilities as the capability to help enterprises effectively cope with turbulent environment. Based on Teece's widely influential research, this study divides the dimensions of dynamic capabilities into sensing opportunities capability, seizing opportunities capability and resource reconfiguration capability. Sensing opportunities capability is to search and identify current or future opportunities and threats of markets and technologies. Seizing opportunities capability is to exploit opportunities by internal and external resources to update products and services. Resource reconfiguration capability is to reconstruct the core resource system, promote enterprise transformation, break through organizational conventions to maintain competitiveness. This study will further explore the impact of various dimensions of dynamic capabilities on 
promoting disruptive innovation.

\section{Entrepreneurial Bricolage}

The resource-based view holds that competitive advantage comes from those valuable and irreplaceable resources. It is a static view of resources. It emphasizes the value of heterogeneous resources, but it does not specify the source of heterogeneous resources. Baker and Nelson [25] put forward the concept of entrepreneurial bricolage and believed that under the resource-constrained environment, entrepreneurs will make use of existing resources to serve new opportunities or challenges, which is an effective way for new enterprises to survive and grow. Their research found that entrepreneurial bricolage included three concepts: immediate action, combination of resources to achieve new goals, and resources at hand. Entrepreneurial bricolage is a dynamic resource view, which expounds the sources of heterogeneous resources, and emphasizes the excavation and compound utilization of existing resources. Witell et al. [26] pointed out that under the predicament of scarcity resources, traditional service innovation methods can not achieve the desired effect, but the effect of service innovation through resource patchwork was better.

Scholars have classified the types of entrepreneurial bricolage from the aspects of bricolage frequency and scope, bricolage objects, bricolage motivation and bricolage orientation. In terms of patching frequency and scope, Baker and Nelson [25] divide the resource bricolage process into "parallel patching" and "continuous patching". According to the classification of bricolage objects, Senyard et al. [27] divided entrepreneurial bricolage into material bricolage, manpower bricolage, skill bricolage, customer bricolage, system bricolage and network bricolage. Based on the criterion of bricolage motivation, entrepreneurial bricolage can be divided into demand-based bricolage and conceptual bricolage. Based on the bricolage orientation, Ye et al. divided the types of entrepreneurial bricolage into resource bricolage, opportunity bricolage and customer bricolage. The multi-angle classification of entrepreneurial bricolage shows that entrepreneurial bricolage theory has aroused great interest of management scholars.

\section{HYPOTHESES DEVELOPMENT}

\section{A. Dynamic Capabilities and Disruptive innovation}

In the process of disruptive innovation development, entrepreneurial enterprises are driven by environmental uncertainties and their capabilities to cope with environmental changes has undergone significant changes. Under this background, the construction of dynamic capabilities is of great significance to promote the process of disruptive innovation.

(1) Sensing opportunities capability and disruptive innovation

In the practice of disruptive innovation, the accurate identification of the direction and timing of disruptive innovation depends on the relevant capabilities of enterprises. Through sensing capability, enterprises can grasp the dynamic changes of national macro-policies, industrial development trends, technological development trends, competition patterns and stakeholder needs, timely perceive opportunities and threats in the external environment, and accurately assess their own resources and capabilities, so as to identify the correct direction and grasp the appropriate timing of disruptive innovation.

(2) Seizing opportunities capability and disruptive innovation

After identifying opportunities, enterprises need to integrate and utilize existing resources quickly. With the help of seizing opportunities capability, it is easier for entrepreneurial enterprises to lay knowledge foundation for the best scheme to develop the above opportunities, rapidly develop new markets or develop new technologies and other innovative achievements to match opportunities, bring new products and effectively implement disruptive innovation.

(3) Resource reconfiguration capability and disruptive innovation

Disruptive innovation need new organizational system and organizational management to support, and require corresponding organizational and cultural changes. The essence of organizational change is the change of organizational management and process. With the help of resource reconfiguration capability, the implicit knowledge of organizational members is gradually transformed into a new understanding of the organization, generating new knowledge, and then promoting the change of operation process and business practices.

Therefore, the following hypotheses are put forward in this study:

H1: Dynamic capability have a positive impact on disruptive innovation.

H1a: Sensing opportunities capability has a positive impact on disruptive innovation.

H1b: Seizing opportunities capability has a positive impact on disruptive innovation.

H1c: Resource reconfiguration capability has a positive impact on disruptive innovation.

\section{B. Entrepreneurial Bricolage and Dynamic Capabilities}

Entrepreneurial bricolage is not an isolated activity. As a resource bricolage and renewal, it is the process of organizational dynamic capabilities building. Entrepreneurial bricolage creative use of existing resources at hand, resulting in valuable new knowledge and information. The knowledge and information, as the most important intangible resources, are the source of differentiation and the basis of dynamic capabilities advantages. In the bricolage mode, the organization maintains its sensitivity to environmental change, wins surprisingly with appropriate strategies, and promotes the sensing opportunities capability. In the bricolage process, the reorganization of existing resources, programmes and actions has strengthened the seizing opportunities capability. Bricolage means innovation, refusing to adhere to conventions. Creative integration from technological capabilities, knowledge information and institutional networks breaks through the constraints of organizational conventions and helps to form the resource reconfiguration capability. Bricolage activities enable entrepreneurs to identify entrepreneurship opportunities 
ahead of competitors in a competitive environment with asymmetric information and low market position, quickly adapt to market changes, strengthen dynamic capabilities and take timely favorable actions to gain competitive advantage.

Therefore, the following hypotheses are put forward in this study:

$\mathrm{H} 2$ : Entrepreneurial bricolage has a positive impact on dynamic capabilities.

$\mathrm{H} 2 \mathrm{a}$ : Entrepreneurial bricolage has a positive impact on the sensing opportunities capability perceived opportunity ability.

$\mathrm{H} 2 \mathrm{~b}$ : Entrepreneurial bricolage has a positive impact on the seizing opportunities capability.

$\mathrm{H} 2 \mathrm{c}$ : Entrepreneurial bricolage has a positive impact on the resource reconfiguration capability.

Based on the above analysis, this study constructs a theoretical model of entrepreneurial bricolage, dynamic capabilities and disruptive innovation, as shown in Fig. 1.

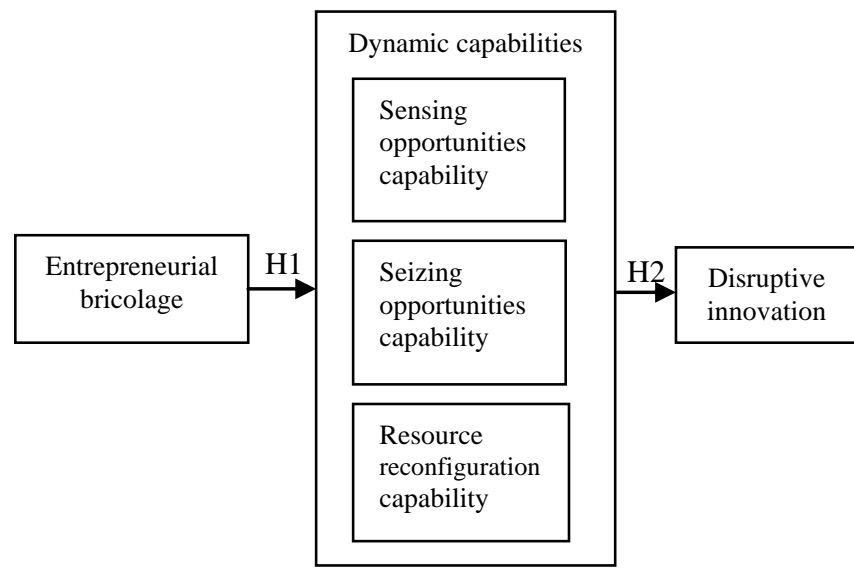

Fig. 1. A theoretical model of entrepreneurial bricolage, dynamic capabilities and disruptive innovation.

\section{CONCLUSION}

There is no complete research on how entrepreneurial bricolage and dynamic capabilities affect disruptive innovation of entrepreneurial enterprises. On the basis of literature research and theoretical discussion, this study constructs a theoretical model of entrepreneurial bricolage, dynamic capabilities and disruptive innovation, and then extracts relevant propositions.

Compared with the previous studies, the main contributions of this paper are as follows: from the comprehensive perspective of resource-based view and dynamic capabilities view, this paper considers that the disruptive innovation is driven by dynamic capabilities that is driven by entrepreneurial bricolage, and constructs a path model of "entrepreneurial bricolage $\rightarrow$ dynamic capabilities $\rightarrow$ disruptive innovation". It is of great significance to enrich, improve and develop the theory of disruptive innovation, and to promote entrepreneurs to enhance their dynamic capabilities in order to cope with resource constraints and dynamic environment and achieve eventually disruptive innovation.

This study only completes the basic work of the theoretical framework of disruptive innovation for entrepreneurial enterprises, and follow-up research can be carried out in two directions. Firstly, typical enterprises are selected for case study and multi-case comparative study to further revise and improve the theoretical framework proposed in this paper. Secondly, on the basis of the theoretical framework and related propositions formed in this paper, large sample enterprises are selected for questionnaire survey to test the theoretical framework and related hypotheses.

\section{CONFLICT OF INTEREST}

The authors declare no conflict of interest.

\section{AUTHOR CONTRIBUTIONS}

C. N. wrote the manuscript; X. M. and T. S. designed research goals; all authors had approved the final version.

\section{REFERENCES}

[1] C. M. Christensen, The Innovator's Dilemma: When New Technologies Cause Great Firms to Fail, Boston: Harvard Business School Press, 1997.

[2] H. Aldrich and E. R. Auster, Even Dwarfs Started Small: Liabilities of Age and Size and Their Strategic Implications, Greenwich: JAI Press, 1986.

[3] L. Wu, "Applicability of the resource-based and dynamic-capability views under environmental volatility," J. Bus. Res., vol. 63, pp. 27-31, 2010 .

[4] R. Reinhardt, and S. Gurtner, "Differences between early adopters of disruptive and sustaining innovations", J. Bus. Res., vol. 68, no. 1, pp. 137-145, 2015.

[5] J. Karimi and Z. Walter, "The role of dynamic capabilities in responding to digital disruption: A factor-based study of the newspaper industry," J. Manage. Inform. Syst., vol. 32, no. 1, pp. 39-81, 2015.

[6] J. Dedrick, M. Venkatesh, J. M. Stanton et al., "Adoption of smart grid technologies by electric utilities: Factors influencing organizational innovation in a regulated environment," Electron. Markets, vol. 25, no. 1, pp. 17-29, 2015

[7] N. Kammerlander, A. König, and M. Richards, "Why do incumbents respond heterogeneously to disruptive innovations? The interplay of domain identity and role identity," J. Manage. Stud., vol. 55, no. 7, pp. 1122-1165, 2018.

[8] A. Ghezzi, L. Gastaldi, E. Lettieri et al., "A role for startups in unleashing the disruptive power of social media," Int. J. Inform. Manage., vol. 36, no. 6, pp. 1152-1159, 2016.

[9] N. Hynes and A. D. Elwell, "The role of inter-organizational networks in enabling or delaying disruptive innovation: A case study of mVoIP," J. Bus. Ind. Mark., vol. 31, no. 6, pp. 722-731, 2016.

[10] J. Dedrick, M. Venkatesh, J. M. Stanton et al., "Adoption of smart grid technologies by electric utilities: Factors influencing organizational innovation in a regulated environment," Electron. Markets., vol. 25, no. 1, pp. 17-29, 2015

[11] M. E. Parry and T. Kawakami, "The encroachment speed of potentially disruptive innovations with indirect network externalities: The case of e-readers," J. Prod. Innov. Manage., vol. 34, no. 2, pp. 141-158, 2017.

[12] J. Karimi and Z. Walter, "The role of dynamic capabilities in responding to digital disruption: A factor-based study of the newspaper industry," J. Manage. Inform. Syst., vol. 32, no. 1, pp. 39-81, 2015.

[13] C. M. Christensen and M. E. Raynor, The Innovators Solution: Creating and Sustaining Successful Growth, Boston, MA: Harvard Business School Press, 2003.

[14] G. M. Schmidt and C. T. Druehl, "When is a disruptive innovation disruptive?” J. Prod. Innov. Manage., vol. 25, no. 4, pp. 347-369, 2008.

[15] V. Govindarajan and P. K. Kopalle, "The usefulness of measuring disruptiveness of innovations ex-post in making ex-ante predictions," $J$. Prod. Innov. Manage., vol. 23, no. 1, pp. 12-18, 2006.

[16] D. Teece, G. Pisano, and A. Shuen, "Dynamic capabilities and strategic management," Strategic Manage. J., vol. 18, pp. 509-533, 1997.

[17] S. G. Winter, "Understanding dynamic capabilities," Strategic Manage. J., vol. 24, pp. 991-995, 2003.

[18] K. M. Eisenhardt and J. A. Martin. "Dynamic capabilities: What are they?" Strategic Manage. J., vol. 21, pp. 1105-1121, 2000.

[19] M. Zollo and S. G. Winter, "Deliberate learning and the evolution of dynamic capabilities," Organ. Sci., vol. 13, pp. 339-351, 2002. 
[20] S. G. Helfat, Dynamic Capabilities: Understanding Strategic Change in Organizations, Oxford: Blackwell, 2007.

[21] D. Teece, "Explicating dynamic capabilities: The nature and microfoumdations of (sustainable) enterprise performance," Strategic Manage. J., vol. 28, pp. 1319-1350, 2007.

[22] C. L. Wang and P. K. Ahmed, "Dynamic capabilities: A review and research Agenda," Int. J. Manage. Rev., vol. 9, no. 1, pp. 31-51, 2007.

[23] I. Barreto, "Dynamic capabilities: A review of past research and an agenda for the future," J. Manage., vol. 36, no. 1, pp. 256-280, 2009.

[24] P. A. Pavlou and O. A. El Sawy, "Understanding the elusive black box of dynamic capabilities," Decision Sci., vol. 42, pp. 239-273, 2011.

[25] T. Baker and R. E. Nelson, "Creating something from nothing: Resource construction through entrepreneurial bricolage," Admin. Sci. Quart., vol. 50, no. 3, pp. 329-366, 2005.

[26] L. Witell, H. Gebauer, E. Jaakkola et al., "A bricolage perspective on service innovation,” J. Bus. Res., vol. 79, no. 3, pp. 290-298, 2017.

[27] J. M. Senyard, P. Davidsson, and P. R. Steffens, "Venture creation and resource processes: Using bricolage sustainability ventures," in Proc. 7th AGSE International Entrepreneurship Research Exchange, 2010.

Copyright $(\odot 2020$ by the authors. This is an open access article distributed under the Creative Commons Attribution License which permits unrestricted use, distribution, and reproduction in any medium, provided the original work is properly cited (CC BY 4.0).

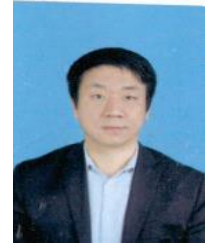

Cao Ning was born in Henan province in China. He is a Ph.D. candidate at the School of Management, Northwestern Polytechnical University. His research is mainly focused on disruptive innovation.

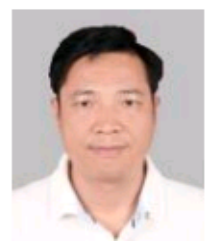

Miao Xiaoming was born in Gansu province in China. $\mathrm{He}$ is a professor at the School of Management, Northwestern Polytechnical University. His research is mainly focused on innovation management, industrial economy.

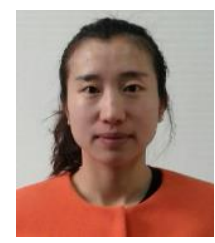

Tian-Tian Shang was born in Shandong province in China. She is a Ph.D. candidate at the School of Management, Northwestern Polytechnical University. Her research is mainly focused on disruptive innovation. 